\title{
A Study of relationship between frailty and physical performance in elderly women
}

\author{
Bog Ja Jeoung ${ }^{1, *}$, Yang Chool Lee ${ }^{2}$ \\ 'Department of Exercise Rehabilitation \& Welfare, College of Health Science, Incheon, Korea \\ ${ }^{2}$ Department of Sports \& Leisure Studies, Gachon University, Seongnam, Korea
}

Frailty is a disorder of multiple inter-related physiological systems. It is unclear whether the level of physical performance factors can serve as markers of frailty and a sign. The purpose of this study was to examine the relationship between frailty and physical performance in elderly women. One hundred fourteen elderly women participated in this study, their aged was from 65 to 80 . We were measured 6-min walk test, gripstrength, 30-sec arm curl test, 30-sec chair stand test, 8 foot Up- and Go, Back scratch, chair sit and reach, unipedal stance, BMI, and the frailty with questionnaire. The collected data were analyzed by descriptive statistics, frequencies, correlation analysis, ANOVA, and simple liner regression using the IBM 21. SPSS program. In results, statistic tests showed that there were significant differences between frailty and 6-min walk test, 30-sec arm curl test, 30-sec chair stand test, gripstrength, Back scratch, and BMI. However, we did not find significant differences between frailty and 8 foot Up- and Go, unipedal stance. When the subjects were divided into five groups according to physical performance level, subjects with high 6-min walk, 30-sec arm curl test, chair sit and reach test, and high grip strength had low score frailty. Physical performance factors were strongly associated with decreased frailty, suggesting that physical performance improvements play an important role in preventing or reducing the frailty.

Keywords: Elderly women, Frailty, Physical performance

\section{INTRODUCTION}

Health issues in elderly adults have recently been emphasized due to the rapid aging of society. During the process of aging, frailty can develop in the elderly, owing to limited exercise capacity, reduced vital capacity, poor muscular strength, restricted flexibility, decreased bone mass, and glucose intolerance. These physiologic changes lead to loss of physical function and dependence on assistance in performing activities of daily living (Chou et al., 2012).

"Frailty" refers to a physiological syndrome distinct from normal aging and dysfunction. The elderly become frail when functions of various organs in the body gradually decline, and biological reserve falls below a certain level. If a disease develops during normal aging, biological and physical functions decrease, and frailty is diagnosed (Jeoung, 2014; Liu and Fielding, 2011; Park et al., 2012).

Frailty is a disorder of multiple interrelated physiological systems. There is a gradual decline in physiological reserve with aging, but in frailty, this decline is accelerated and homeostatic mechanisms start failing (Ferrucci et al., 2002). An important consideration in frailty, therefore, is to consider how the complex mechanisms of aging promote cumulative decline in multiple physiological systems, with consequent erosion of homeostatic reserves and vulnerability to disproportionate changes in health status, following relatively minor stressful events. The frail elderly tend to depend on others due to limitations of physical function compared to the normal elderly, and maintenance of function is more important to the elderly than healing from diseases (Kang, 2007; Lee et al., 2013).

Frailty, a primary pathway to disability, has been defined as a pathological condition that results in a constellation of signs and
${ }^{*}$ Corresponding author: Bog Ja Jeoung

Department of Exercise Rehabilitation \& Welfare, College of Health Science,

191 Hambakmoei-ro, Yeonsu-gu, Incheon 21936, Korea

Tel: +82-32-820-4766; Fax: +82-32-820-4049, E-mail: bogja05@gachon.ac.kr

Received: July 9, 2015 / Accepted: August 5, 2015
This is an Open Access article distributed under the terms of the Creative Commons Attribution Non-Commercial License (http://creativecommons.org/licenses/by-nc/3.0/) which permits unrestricted non-commercial use, distribution, and reproduction in any medium, provided the original work is properly cited. 
symptoms, and is characterized by high susceptibility to adverse health outcomes, impending decline in physical function, and high risk of death (Ferrucci et al., 2004; Fried et al., 2004).

Exercise is a key intervention for improving physical function in older adults. The American College of Sports Medicine recommends aerobics, muscle strengthening, and flexibility exercise for older people. Previous studies have shown that physical fitness is a strong independent predictor of mortality (Park et al., 2012). Individuals with high physical fitness may have greater muscle mass and quality, and greater reserve capacity to resist physical stress. Therefore, improvement in the physical fitness of elderly individuals through appropriate exercise should enable them to maintain their daily activity into later years of life. A number of studies reported that various modes of regular exercises improved physical fitness, and were helpful in prevention of frailty (Chou et al., 2012; Lee et al., 2013; Liu and Fielding, 2011; Person et al., 2009).

Kang (2007) reported that reduction of health-related physical fitness correlated with aging; intervention would be most important for improvement and maintenance of physical fitness in women, because women experience an earlier decline of health-related physical fitness, and age faster compared to men. Although Song and Kim (2013) suggested a standard of physical fitness for elderly women in rural areas, they were not able to suggest a standard to prevent the elderly from being frail. Thus, it is necessary to study the correlation of frailty with the level of physical fitness to slow the rate of aging. The present study aimed to propose a standard of physical performance to prevent the elderly from becoming frail, and to provide basic data for the development of a rehabilitative exercise program based on this standard.

\section{MATERIALS AND METHODS}

\section{Participants}

A total of 114 elderly women 65-80 yr old, who live in Incheon metropolitan, participated in this study. All potential participants underwent a comprehensive explanation of the proposed study, its benefits and inherent risks, and the expected time commitment. Medical information (health status and medications) was obtained from participants u sing a questionnaire. The subjects were excluded if they were not able to walk without a cane or other assistive device, or had known conditions and musculoskeletal problems limiting their safe participation in this study. Participant demographics are shown in Table 1.
Table 1. Demographic of participants

$(n=114)$

\begin{tabular}{lc}
\hline Variable & $\mathrm{M} \pm \mathrm{SD}$ \\
\hline Age $(\mathrm{yr})$ & $74.1 \pm 7.8$ \\
Height $(\mathrm{cm})$ & $153.1 \pm 5.0$ \\
Weight $(\mathrm{kg})$ & $76.4 \pm 17.9$ \\
BMl & $32.5 \pm 8.0$ \\
6-min walk (m) & $499.71 \pm 120.8$ \\
30-sec chair stand test (sec) & $15.6 \pm 5.1$ \\
30-sec arm curl test (time) & $35.9 \pm 11.6$ \\
chair sit and reach test (cm) & $8.3 \pm 9.7$ \\
back scratch test (cm) & $-10.7 \pm 13.2$ \\
8-foot up and go test (sec) & $6.6 \pm 7.1$ \\
unipedal stance (sec) & $6.2 \pm 9.6$ \\
grip strength (kg) & $35.9 \pm 11.6$ \\
Frailty (score) & $8.03 \pm 5.6$ \\
\hline
\end{tabular}

\section{Instruments}

\section{Physical performance test}

The physical performance test for seniors included a 6-min walk test, grip strength, 30-second arm curl test, 30-sec chair stand test, back scratch test, chair sit and reach test, 8 foot up and go test, unipedal stance, and body mass index (BMI).

\section{Frailty assessment}

The frailty assessment is a basic measurement tool originally developed by the Ministry of Health, Labour and Welfare of Japan to select subjects for preventive health care. It was revised and supplemented by the Korea Institute for Health and Social Affairs to accommodate the Korean language (Park et al., 2012). It measures the frailty of older adult participants and consists of 5 lifestyle function questions, 5 physiological motor function questions, 2 nutrition status questions, 3 oral health function questions, 2 social capacity questions, and 3 cognitive function questions (total of 20 questions). The tool is composed of 25 questions and 7 subcategories and 5 questions related to depression prevention and support. The examiner reads sentences, and records 1 point for "Yes", and 0 for "No", with scores ranging from 0 to 25 points; a higher score indicates a greater degree of frailty.

\section{Statistical analysis}

Statistical analysis was performed using SPSS for Windows version 21 (IBM SPSS Inc., Chicago, IL, USA). A correlation analysis was conducted to examine the correlation between frailty and physical performance factors, and the correlated physical performance factors were divided into quartiles to analyze the differenc- 
Table 2. Correlation between frailty and physical fitness

\begin{tabular}{|c|c|c|c|c|c|c|c|c|c|}
\hline Variable & $\begin{array}{l}\text { 6-min } \\
\text { walk }\end{array}$ & $\begin{array}{c}30 \text {-sec } \\
\text { chair stand test }\end{array}$ & $\begin{array}{c}30 \text {-sec } \\
\text { arm curl test }\end{array}$ & $\begin{array}{c}\text { Chair sit } \\
\text { and reach test }\end{array}$ & $\begin{array}{c}\text { Back } \\
\text { scratch test }\end{array}$ & $\begin{array}{l}\text { 8-foot up } \\
\text { and go test }\end{array}$ & $\begin{array}{l}\text { Unipedal } \\
\text { stance }\end{array}$ & $\begin{array}{c}\text { Grip } \\
\text { trength }\end{array}$ & BMI \\
\hline Frailty & $-0.251^{* *}$ & $-0.249^{*}$ & $-0.375^{* *}$ & $-0.321^{* *}$ & -0.168 & 0.133 & 0.135 & $-0.276^{* *}$ & $0.415^{* * *}$ \\
\hline
\end{tabular}

${ }^{* * *}$ represents $P<0.001$. ${ }^{* *}$ represents $P<0.01$. * represents $P<0.05$.

Table 3. Frailty according to physical fitness factor

\begin{tabular}{|c|c|c|c|c|c|}
\hline & \multicolumn{5}{|c|}{ Frailty } \\
\hline & $b$ & $\beta$ & $\mathrm{R}^{2}$ & $t$ & $P$ \\
\hline 6-min walk test & -0.013 & -0.251 & 0.005 & -2.72 & $0.007^{* *}$ \\
\hline 30-sec arm curl test & -0.185 & -0.375 & 0.133 & -4.27 & $0.000^{* * *}$ \\
\hline 30-sec chair stand test & -0.294 & -0.249 & 0.052 & -2.52 & $0.013^{*}$ \\
\hline grip-strength & -0.488 & -0.276 & 0.067 & -2.92 & $0.004^{* *}$ \\
\hline chair sit and reach test & -0.214 & -0.321 & 0.095 & -358 & $0.000^{* * *}$ \\
\hline $\mathrm{BMI}$ & 0.333 & 0.415 & 0.164 & 4.71 & $0.000^{* * *}$ \\
\hline
\end{tabular}

*** represents $P<0.001$. ${ }^{* *}$ represents $P<0.01$. ${ }^{*}$ represents $P<0.05$.

es between groups. Data were analyzed using linear regression and descriptive statistics. The significance threshold was set at 0.05 .

\section{RESULTS}

There were significant correlations between the 6 min walk test (aerobic capacity), $30 \mathrm{sec}$ chair stand test (endurance strength of the lower limbs), 30 sec arm curl test (endurance strength of the upper limbs), chair sit and reach test (flexibility), hand grip strength, BMI (body composition), and frailty (Table 2).

When the effects of physical performance factors on frailty were analyzed by linear regression analysis, frailty scores decreased as values increased for the 6 min walk, $30 \mathrm{sec}$ chair stand test, $30 \mathrm{sec}$ arm curl test, chair sit and reach test, and grip strength, whereas an increase of BMI increased the frailty score (Table 3).

When levels of physical performance factors were divided into quintiles and comparatively analyzed, the group of elderly women with 6 min walk test values in the lowest quintile had a frailty mean score as high as 9.54; those with a $30 \mathrm{sec}$ chair stand test value in the lowest quintile had a frailty mean score as high as 11.15 .

The lowest quintile in the chair sit and reach test had a frailty score as high as 10 . Those in the lowest quintile for BMI, with a value greater than 36.9, had the highest frailty score, 11.95 (Table 4).

\section{DISCUSSION}

Aging is associated with difficulties in daily life, with geriatric chronic diseases such as hypertension, diabetes, and arthritis, and decreased levels of physical activity, which lead to decline in physical fitness. Although it is not possible to completely prevent the decline due to disease patterns in old age, exercise designed to slow the decline or to improve physical fitness are most important. An improvement in physical fitness through exercise reportedly also enhances balance and the function of neurotransmitters, and positively affects maintenance of the neuroendocrine and autonomic nervous systems and cerebral morphology, thus contributing to prevention of frailty in the elderly (Narazaki et al., 2014). However, basic data on the level of physical performance necessary for prevention of frailty are lacking. The present study analyzed correlations and effects of frailty and physical performance factors in elderly women in Incheon, in order to propose a standard of physical fitness for prevention of frailty. The study found that frailty was affected by the 6 min walk test, 30 sec chair stand test, $30 \mathrm{sec}$ arm curl test, chair sit and reach test, grip strength, and BMI. In addition, the very weak group, corresponding to the lowest quintile in level of cardiovascular function, muscle strength, muscular endurance, obesity, and physical fitness, had a much higher frailty level than the group with very good levels, corresponding to the highest quintile, as presented in Table 4. The standard of physical fitness for elderly women in a rural area proposed by Song and Kim (2013) was lower than the standard for frailty prevention in the present study. This discrepancy is probably due to the smaller number of participants in the present study. However, the results of this study are significant because we proposed a standard of physical performance to prevent frailty, and 
Table 4. Difference of frailty according to physical performance level

\begin{tabular}{|c|c|c|c|c|c|c|}
\hline & $\begin{array}{c}\text { Very weak } \\
(1-20 \%)\end{array}$ & $\begin{array}{c}\text { Weak } \\
(20-40 \%)\end{array}$ & $\begin{array}{l}\text { Average } \\
(40-60 \%)\end{array}$ & $\begin{array}{c}\text { Good } \\
(60-80 \%)\end{array}$ & $\begin{array}{l}\text { Very good } \\
(80-100 \%)\end{array}$ & $P$ \\
\hline 6-min walk test (m) & $\begin{array}{c}<409.6 \\
n=22\end{array}$ & $\begin{array}{c}409.7-487 \\
n=23\end{array}$ & $\begin{array}{c}487.1-523 \\
n=23\end{array}$ & $\begin{array}{c}523.1-597 \\
n=23\end{array}$ & $\begin{array}{l}>597 \\
n=23\end{array}$ & \\
\hline Frailty & $9.54 \pm 4.7$ & $9.26 \pm 4.0$ & $8.52 \pm 7.1$ & $5.82 \pm 3.9$ & $5.32 \pm 4.4$ & $0.025^{*}$ \\
\hline 30-sec arm curl test (times) & $\begin{array}{c}<27 \\
n=26\end{array}$ & $\begin{array}{l}27-35 \\
n=21\end{array}$ & $\begin{array}{l}35-41 \\
n=24\end{array}$ & $\begin{array}{l}41-47 \\
n=21\end{array}$ & $\begin{array}{c}>47 \\
n=22\end{array}$ & \\
\hline Frailty & $11.15 \pm 6.0$ & $8.7 \pm 4.3$ & $7.5 \pm 6.8$ & $7.52 \pm 4.6$ & $4.68 \pm 3.5$ & $0.002^{* *}$ \\
\hline 30-sec chair stand test (time) & $\begin{array}{c}<12 \\
n=23\end{array}$ & $\begin{array}{l}12-15 \\
n=24\end{array}$ & $\begin{array}{l}15-18 \\
n=29\end{array}$ & $\begin{array}{l}18-19 \\
n=17\end{array}$ & $\begin{array}{c}>19 \\
n=21\end{array}$ & \\
\hline Frailty & $10.04 \pm 6.5$ & $8.7 \pm 6.9$ & $6.0 \pm 4.2$ & $8.3 \pm 5.7$ & $6.05 \pm 4.1$ & 0.079 \\
\hline Grip-strength (kg) & $\begin{array}{c}<12 \\
n=22\end{array}$ & $\begin{array}{l}12-15 \\
n=23\end{array}$ & $\begin{array}{l}17-18 \\
n=25\end{array}$ & $\begin{array}{l}18-19 \\
n=21\end{array}$ & $\begin{array}{c}>19 \\
n=23\end{array}$ & \\
\hline Frailty & $10.71 \pm 8.7$ & $8.8 \pm 5.3$ & $8.17 \pm 3.7$ & $8.21 \pm 5.3$ & $6.0 \pm 3.9$ & 0.104 \\
\hline Chair sit and reach test & $\begin{array}{c}<3 \\
n=24\end{array}$ & $\begin{array}{c}3-8 \\
n=28\end{array}$ & $\begin{array}{c}8-11 \\
n=24\end{array}$ & $\begin{array}{l}11-17 \\
n=12\end{array}$ & $\begin{array}{c}>17 \\
n=26\end{array}$ & \\
\hline Frailty & $10.0 \pm 6.9$ & $9.68 \pm 5.2$ & $7.42 \pm 4.5$ & $7.2 \pm 3.8$ & $5.58 \pm 4.4$ & $0.033^{*}$ \\
\hline $\mathrm{BMI}$ & $\begin{array}{c}>36.96 \\
n=23\end{array}$ & $\begin{array}{c}36.96-30.12 \\
n=22\end{array}$ & $\begin{array}{c}30.12-24.65 \\
n=22\end{array}$ & $\begin{array}{c}24.65-21.54 \\
n=24\end{array}$ & $\begin{array}{c}<21.54 \\
n=23\end{array}$ & \\
\hline Frailty & $11.95 \pm 2.7$ & $10.87 \pm 8.7$ & $7.28 \pm 3.3$ & $6.42 \pm 4.9$ & $5.47 \pm 4.1$ & $0.000^{* * *}$ \\
\hline 8-foot up and go & $\begin{array}{l}<4.59 \\
n=23\end{array}$ & $\begin{array}{c}4.59-5.43 \\
n=24\end{array}$ & $\begin{array}{c}5.43-6.18 \\
n=22\end{array}$ & $\begin{array}{c}6.18-7.35 \\
n=23\end{array}$ & $\begin{array}{l}>7.35 \\
n=22\end{array}$ & \\
\hline Frailty & $9.69 \pm 8.2$ & $5.78 \pm 4.3$ & $6.3 \pm 4.2$ & $8.6 \pm 4.4$ & $9.8 \pm 4.9$ & 0.193 \\
\hline $\begin{array}{l}\text { Unipedal stance } \\
\text { Frailty }\end{array}$ & $\begin{array}{c}<2.04 \\
n=23 \\
7.34 \pm 6.8\end{array}$ & $\begin{array}{c}2.04-2.8 \\
n=24 \\
8.56 \pm 6.8\end{array}$ & $\begin{array}{c}2.8-4.17 \\
n=22 \\
7.04 \pm 4.1\end{array}$ & $\begin{array}{c}4.17-6.7 \\
n=23 \\
7.52 \pm 4.7\end{array}$ & $\begin{array}{c}>6.7 \\
n=22 \\
9.7 \pm 5.0\end{array}$ & 0.478 \\
\hline $\begin{array}{l}\text { Back scratch test } \\
\text { Frailty }\end{array}$ & $\begin{array}{c}<-20 \\
n=23 \\
8.56 \pm 6.4\end{array}$ & $\begin{array}{c}-6.3 \\
n=24 \\
10.6 \pm 7.0\end{array}$ & $\begin{array}{c}-128.4 \\
n=22 \\
6.7 \pm 4.0\end{array}$ & $\begin{array}{c}-9.6 \\
n=23 \\
6.5 \pm 4.8\end{array}$ & $\begin{array}{c}>1 \\
n=22 \\
8.0 \pm 4.9\end{array}$ & 0.090 \\
\hline
\end{tabular}

${ }^{* * *}$ represents $P<0.001$. ${ }^{* *}$ represents $P<0.01$. ${ }^{*}$ represents $P<0.05$.

the data could be further used to develop corresponding exercise programs. A standard was higher than that of the present study, which may be due to the differences in physical fitness between foreign and Korean elderly women. The present study did not propose a standard of physical performance for frailty prevention by age group and gender, and this should be done in a future study.

Physical fitness testing is very important for evaluation of how efficiently the elderly can perform activities of daily living. The Korean government introduced the National Fitness 100 program to maintain and promote public health. This governmental program also measures muscular endurance of the upper and lower limbs, and cardiovascular endurance in the elderly, using the same measurement items that are variables of physical fitness in the present study. Therefore, the results of this study of functional and physical fitness levels of elderly women can be used to predict the risk of frailty. Further studies are necessary to develop exercise in- tervention programs and methods to prevent the elderly from becoming frail and to promote their health.

\section{CONFLICT OF INTEREST}

No potential conflict of interest relevant to this article was reported.

\section{REFERNCES}

Chou C, Hwang C, Wu Y. Effect of exercise on physical function, daily living activities, and quality of life in the frail older adults. Arch Phys Med Rehabil 2012;93:237-244.

Ferrucci L, Cavazzini C, Corsi A, Bartali B, Russo CR, Lauretani F, Corsi AM, Bandinelli S, Guralnik JM. Biomarkers of frailty in older persons. J Endocrinol Invest 2002;25:5-10.

Ferrucci L, Guralnik J, Studenski S, Fried L, Cutler G, Walston J. Design- 
ing randomizd, controlled trials aimed at preventing or delaying functional decline and disability in frail, older persons; a consensus report. J Am Geriatr Soc 2004;52:625-634.

Fried L, Ferrucci L, Darer J, Williamson J, Anderson G. Untangling the concepts of disability, frailty, and comorbidity: implications for improving targered cre. J Gerontol A Biol Sci Med Sci 2004;59:255-263.

Jeoung BJ. Relationships of exercise with frailty, depression, and cognitive function in elderly women. J Eexerc Rehabil 2014;10:291-294.

Kang S J. Comparison of aging threshold and aging coefficient in health related physical fitness on Korean and Japanese. Korea J Phys Educ 2007;46:723-736.

Lee BA, Kim J, Oh DJ. The effects of combined exercise intervention on body composion and physical fitness in elderly females at a nursing home. J Eexerc Rehabil 2013;9:298-303.

Liu CK, Fielding RA. Exercise as an intervention for frailty. Clin Geriatr Med 2011;27:101-110.

Narazaki K, Matsuo E, Honda T, Nofuji Y, Yonemoto K, Kumagai S. Physical fitness measures as potential markers of low cognitive function in Japanese community-dwelling older adults without apparent cognitive problems. J Sports Sci Med 2014;13:590-596.

Park Y, Lee K, Kim T, Jeon M, Kim D, Kim J. The effects of exercise in the frail elderly. J Korean Acad Community Health Nurs 2012;23:91-101.

Song M., Kim S. The study of criterion for physical fitness using senior fitness test of elderly women in the rural community. Korea J Growth Develop 2013;21:137-142. 